\title{
AN ACTIVE POWER FILTER AT OPERATION ON THE UNBALANCED AND NONLINEAR LOADS WITH CONTROL BY OPTIMIZATION ALGORITHM
}

\begin{abstract}
Purpose is to develop a method for controlling a power active filter based on search optimization using software of Mathlab package and applying this method for balancing and compensating for all components of reactive power in a three-phase system feeding unbalanced linear and nonlinear loads simultaneously. Methodology consists in the development of a visual model of the power supply system that supplies unbalanced and non-linear loads, to the connection points of which a power active filter on IGBT transistors is connected according to a parallel type scheme. We propose an algorithm for calculating the chosen optimization criterion using a visual model, linking the visual model with an optimizing program, and performing a search engine optimization process using an embedded program that implements the deformable polyhedron algorithm. Results lead to an optimal mode, which is characterized by the amplitudes of the control signals of the power active filter control system determined by the search, as well as the initial value of the voltage on the filter energy exchange capacitor. Originality lies in the fact that the proposed method of controlling the operation of the power filter makes it possible to dispense with the construction of a relatively complex filter control system based on Clark's mathematical transformations. Practical value lies in the fact that finding a quasisteady-state optimal mode of the power supply system with a power active filter is performed automatically in the process of search optimization with a simplified control system. The above principles can be implemented in the microprocessor control system for power active filters. References 9 , figures 4.
\end{abstract}

Key words: search optimization, visual model, three-phase power supply system, reactive power, power active filter.

Статья посвящена исследованию трехфазной четырехпроводной системы электроснабжения, питающей несимметричную трехфазную и однофазную нелинейную нагрузки. Силовой активный фильтр представляет собой четырехплечевой мостовой инвертор на IGBT транзисторах. Инвертор питается от энергообменного конденсатора и инжектирует корректирующие токи через буферные реакторы. В отличие от классической системы управления, основанной на преобразованиях Кларк для напряжений и токов, в рассматриваемом варианте предложено управление источниками эталонных сигналов, априори имеющими синусоидальную форму и совпадающими с фазами питающих источников электрической энергии. Определение необходимых амплитуд эталонных сигналов составляет сущность задачи поисковой оптимизации. Оптимизация осуществляется методом деформируемого многогранника с использованием визуальной модели системы электроснабжения с силовым активным фильтром. По завершении оптимизации система приходи к оптимальному режиму, характеризующемуся полной компенсацией всех составляющих реактивной мощности. Библ. 9, рис. 4.

Ключевые слова: поисковая оптимизация, визуальная модель, трехфазная система электроснабжения, реактивная мощность, силовой активный фильтр.

Introduction. Unbalanced and nonlinear loads in three-phase power supply systems give rise to a number of problems associated, ultimately, with reactive power. Circulation of reactive power in the system in turn leads to an increase in the currents in the power lines, an increase in irreversible heat losses in the wires, overheating and premature failure of the insulation of electrical devices [1]. In this regard, the issues of balancing and compensation of reactive power in power supply systems represent a great and unflagging interest in recent decades. A number of works in this area are related to research on the physical nature of reactive power and mathematical interpretations of its behavior, depending on the causes of its appearance [2]. In this respect, a departure from the traditional ideas that emerged in the 20-50th of the last century and the identification of the weaknesses of these theories [3, 4] is characteristic. The need to apply new theories based, in particular, on the use of the concept of instantaneous power, is dictated by the development of control systems for power active filters [4-8], which can fundamentally solve the problems associated with asymmetry and nonsinusoidality of voltages and currents in three-phase power supply systems. Power circuits of active filters are built on the basis of three-phase inverters on IGBT transistors with an energy-exchange capacitor charged through shunt back diodes. The generated corrective currents through the buffer reactors are injected into the power supply system at the load connection points for the case of a parallel active filter. The responsible element of the power active filter is the transistor control system which is an intelligent device containing rather complex computational blocks realized with the help of microcontrollers. The tradition of designing control systems based on the use of Clark transformations and the theory of instantaneous power has already been established [5-7]. At the same time, there are still attempts to apply other approaches for controlling power active filters, in particular, based on the application of search engine optimization algorithms [9]. These algorithms presuppose finding a quasi-steady-state mode of the power supply system with an active filter using software optimization tools, thereby making it possible to eliminate these traditional transformations and obtain optimal solutions for the desired mode.

The goal of the work is to apply search optimization methods to find a quasi-steady-state mode of the three-phase power supply system with a power active filter of parallel type while simultaneously feeding a three-phase asymmetrical active-inductive load and a nonlinear valve load.

The main material of investigations. A visual model of the power supply system under investigation is shown in Fig. 1. 


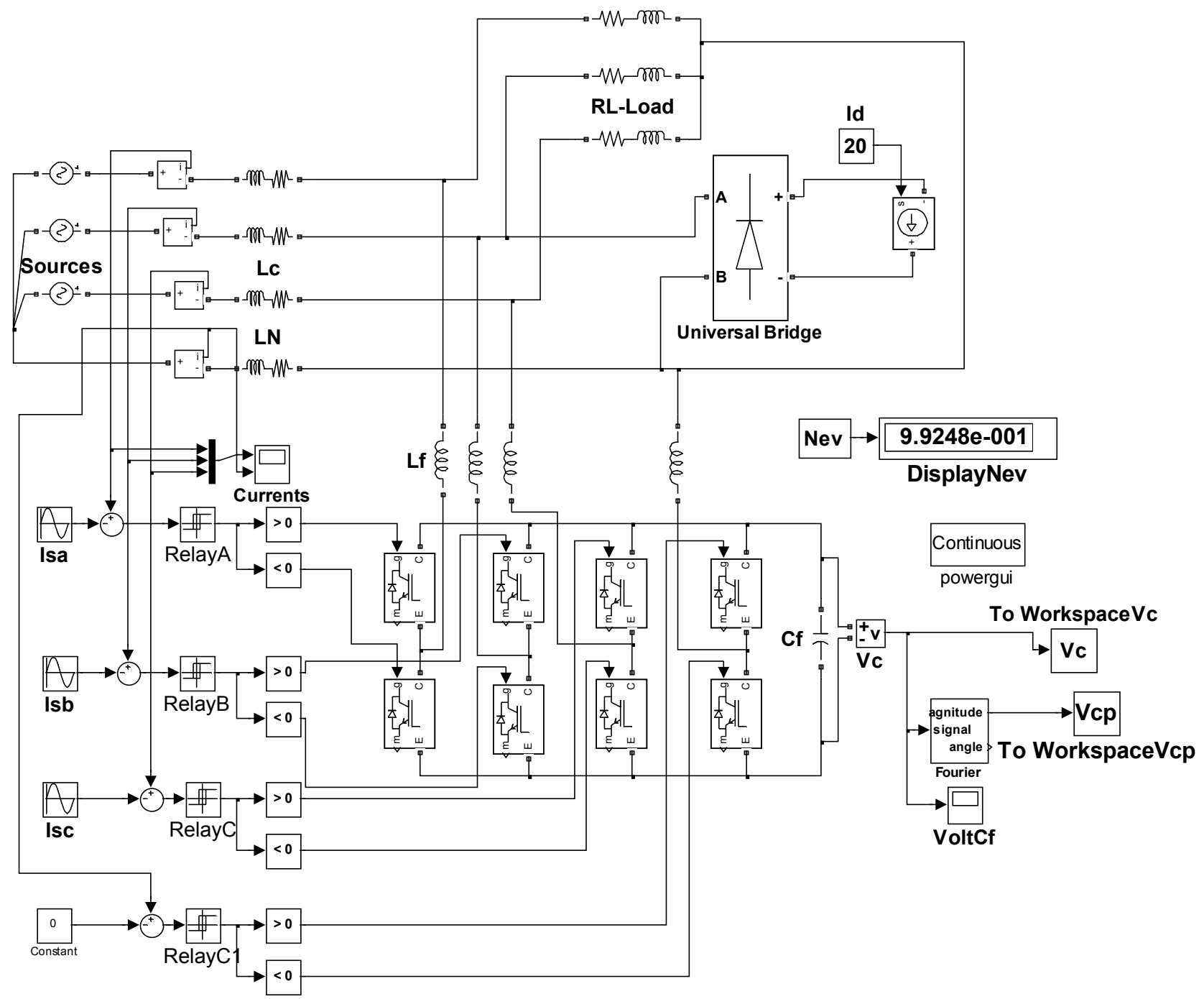

Fig. 1. A visual model of the system under investigation

Here, the supplying three-phase symmetric network of infinite power is represented by voltage sources Sources having a normalized amplitude of $100 \mathrm{~V}$ and a frequency of $50 \mathrm{~Hz}$. Power transmission lines, unlike [2], are not included in the load, but are considered separately and, therefore, are not covered by a power active filter. They are represented by active-inductive elements $L_{c}$, resistor resistances of which are assumed to be equal to $0.1 \Omega$, and inductance $0.001 \mathrm{H}$. The resistance and inductance of the neutral wire $L_{N}$ are three times higher than the corresponding values of the transmission line parameters. The three-phase unbalanced linear load RLLoad according to the star circuit connected to the neutral wire has the following phase parameters: $R_{a}=1.5 \Omega$, $L_{a}=0.025 \mathrm{H}, R_{b}=1.0 \Omega, L_{b}=0.01 \mathrm{H}, R_{c}=2.0 \Omega, L_{c}=0.04 \mathrm{H}$. The non-linear load is represented by a single-phase bridge rectifier Universal Bridge. It is connected to phase $\mathrm{B}$ at the point of connection of the linear load and to the neutral wire, so the rectifier is fed by phase voltage. The load of the rectifier is controlled by a constant current source of fixed value $I_{d}=20 \mathrm{~A}$. The power block of the active filter is represented as an inverter by four shoulders of IGBT transistors, each of which is shunted by a reverse diode. Through the reverse diodes, the energy-exchange capacitor $C_{f}$ is charged, which actually feeds the active filter, for which it is necessary to ensure the charge of this capacitor to a voltage exceeding the amplitude of the line voltage of the network at the connection points of the loads. To these points, correcting currents taken from the diagonals of the inverter bridges are fed through the buffer reactors $L_{r}$. These currents should provide sinusoidal currents in the transmission lines that coincide in phase with the phase voltages of the respective power supplies.

The control system of the active filter is built according to the relay principle. It is implemented with the help of four relay elements Relay, with the outputs of which the signals are divided into two channels using the elements of comparison with zero. The resulting pairs of impulse signals are fed to the transistors of the upper and lower arms of the corresponding phase. In this way, pulse-width modulation is implemented, thanks to which the correcting currents of the active filter are formed. To generate signals using the relay principle, currents in power lines and neutral conductors are taken with current meters. Further, from the received signals, reference signals are subtracted, the shape of which must be repeated as a result of the action of the correcting filter currents in the load lines and in the neutral wire. Therefore, the reference signals $I_{s a}, I_{s b}, I_{s c}$ for the phases 
A, B, C are respectively given in the form of a threephase symmetric system of sinusoids similar to sinusoids of supply voltages of the power supply system. Since the neutral wire must be completely unloaded, the reference signal for it is given by a zero-constant source. Under such conditions, only the amplitude of the reference signals, which ensures this regime, remains unknown for reaching the quasi-steady state.

Unbalanced mode with the power filter off is characterized by non-sinusoidality and non-linearity of currents and voltages in the system and overloading of the neutral current wire. In Fig. 2 three currents in the transmission lines (upper diagrams) and current in the neutral wire are shown. It is seen that the current in phase $\mathrm{B}$, which is loaded with a rectifier, reaches an amplitude of $40 \mathrm{~A}$, and the current in the neutral wire is $25 \mathrm{~A}$, which is twice the amplitudes of the linear currents of phases A and C. All currents have pronounced non-sinusoidal shape which means the presence in the system of currents of higher harmonics and reactive power distortions.
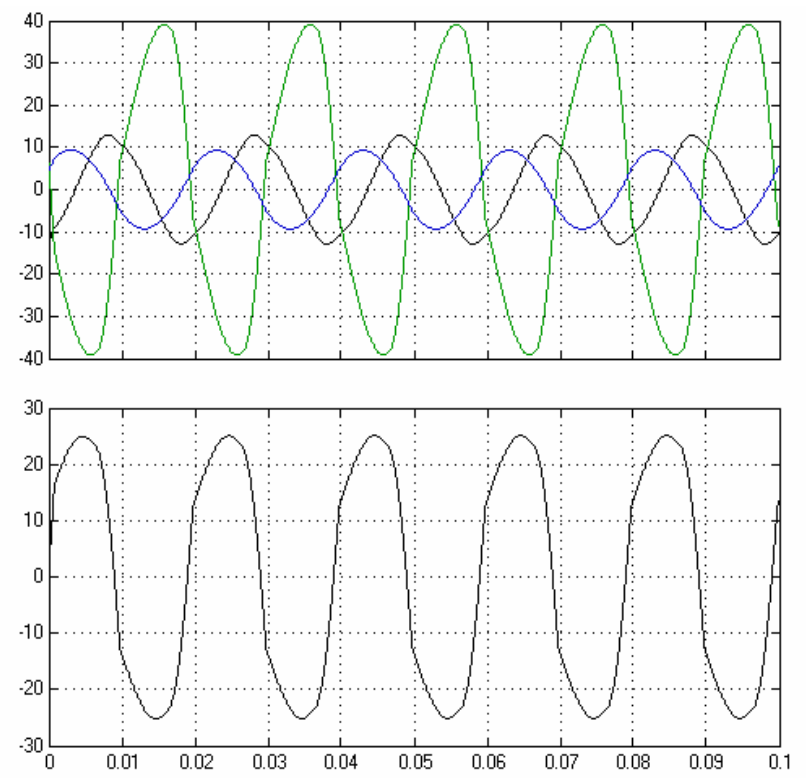

Fig. 2. Currents at the unbalanced mode

Optimization of the mode is carried out when the power filter is connected by Mathlab software using the presented visual model. The optimization is based on the requirement of specifying such a single value of the amplitudes of the reference signals for the phases at which a quasi-steady-state regime takes place in the system. It is characterized by the establishment of periodic currents and voltages on all elements of the system. In particular, the voltage on the energy-exchange capacitor must represent the sum of the constant and the variable components. The constant component of the voltage across the capacitor, as indicated above, must exceed the amplitude of the line voltage. The voltage pulsations on the capacitor, representing the alternating component, depend on the load and capacitance of the energy-exchange capacitor. From the point of view of the efficiency of the filter, we can assume that this capacitance is infinite, and in this case plays the role of a voltage source. In this case, ripple will be absent.
However, in practice the capacity of the energy-exchange capacitor is finite (in the model its value is assumed equal to $600 \mu \mathrm{F}$ ). With a finite value of capacitance of the capacitor, the voltage on it reflects the difference between the amplitude of the reference signal and the optimum value. When this value is exceeded, excess energy enters the system and the voltage on the energy-exchange capacitor tends to increase, reaching in the asymptotics a certain very large value corresponding to the balance of active powers. If the amplitude of the reference signal is insufficient, the voltage on the energy-exchange capacitor tends to decrease due to the lack of energy entering the system, reaching zero in the asymptotics which does not at all correspond to the normal operating conditions of the power active filter. Thus, the voltage on the energyexchange capacitor of the filter, provided that its capacity is finite, is an indicator of the achievement of the optimal compensated regime in the system.

The optimization software is taken from the standard Matlab library, where there are such non-linear optimization programs as fminsearch() that implements the deformable polyhedron algorithm, and fminunc() using the conjugate gradient method. Both programs are easily interchangeable with changing the name by which they are called, the arguments for both functions can be the same. As the optimization variables, the amplitude of the reference signal of the control system and the initial voltage on the energy-exchange capacitor are used. The objective function is formed from discrete voltage values on the energy-exchange capacitor. These values are output at the run interval of the visual model for five periods of the supply voltage with a sampling interval equal to the period of the supply voltage. To form the objective function, the differences of adjacent discrete values are compiled, from which the spherical metric is formed. In addition, the condition for achieving discrete values of a given level (it was assumed to be $400 \mathrm{~V}$ ) was also introduced. Thus, when the model is run, discrete values are transferred to the working area of Matlab, where they are picked up by an additional function that executes the visual model and then calculates the value of the objective function, which is then passed to the parent program that calls the optimization function. Fig. 1 shows the state of the model after reaching the minimum, where you can see the value of the objective function in the form of the global constant $N_{e v}=0.99248$, which sufficiently accurately determines the compensated mode in the system. The amplitudes of the reference signals in this case were $I_{s m}=12.369$ A. From this value, $4.243 \mathrm{~A}$ are incident on the supply of an asymmetric linear load, as shown in [10], and the remaining fraction of 8.126 $\mathrm{A}$ is due to the supply of a nonlinear load to the rectifier. The fairness of this distribution is illustrated by a simple estimate of the fraction of active power consumed by the rectifier. Fig. 3 shows the current diagrams in the lines of the neutral wire in the compensated mode (similar to the diagrams in Fig. 2). It is seen that the amplitudes of the linear currents are equalized, and their phases coincide with the phases of the supply voltages. The current in the neutral wire is almost gone. This indicates a complete balancing and balancing of the mode in the power supply system. 
Fig. 4 shows the voltage diagram on the energyexchange capacitor. It starts with the voltage at the zero moment $V_{c o}=401.562 \mathrm{~V}$ found during the search optimization and forms a vector of discrete quantities $V_{c}=[400.099,399.878,399.885,399.356,399.179]$ that testify to the provision of a given stable voltage on the energy-exchange capacitor within the specified error.
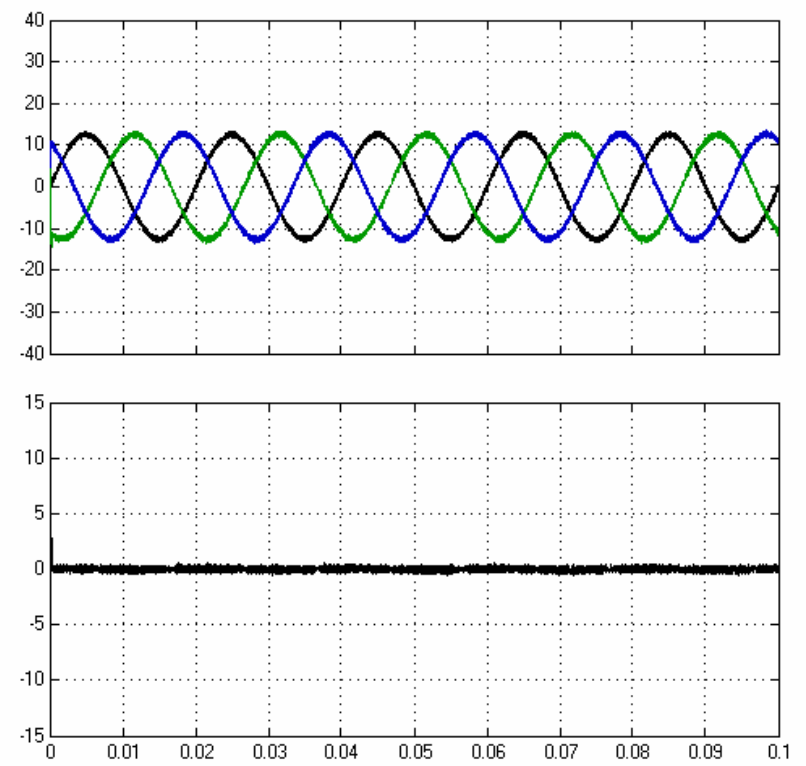

Fig. 3. Current at the balanced mode

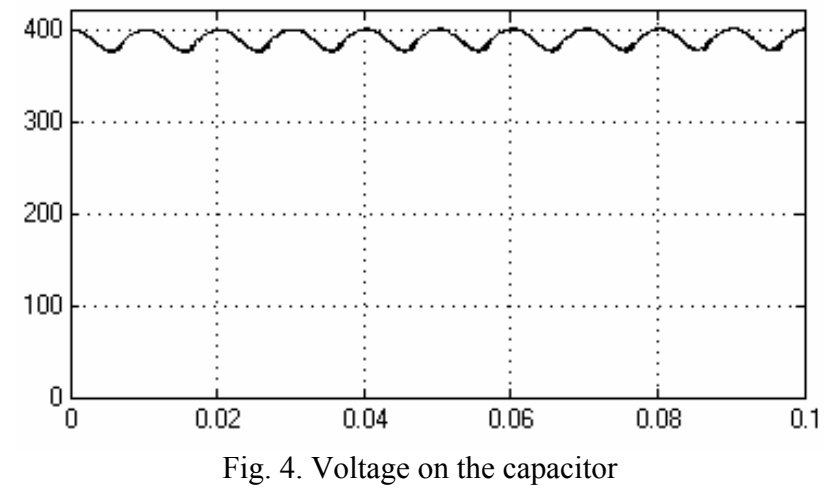

Conclusions. The research carried out shows that the proposed algorithm for active filter control based on the application of search optimization in conjunction with the visual model of the power supply system makes it possible to determine the quasi-steady state of the system and to reach the optimal mode of full compensation of all components of reactive power when feeding asymmetrical linear and nonlinear loads. It is possible to form the target function from the discrete voltage values on the energyexchange capacitor, and use the amplitude of the reference sinusoidal signal for the proposed control system and the initial value of the voltage on the energyexchange condenser as optimization variables. An introduction to the expression for the objective function of the voltage stabilization parameter on the energyexchange capacitor also allows to set the proper level of the voltage over the capacitor above the amplitude of the line voltage of the network, thus providing the necessary direction of the energy flow from the filter to the network.

\section{REFERENCES}

1. Acha E., Agelidis V.G., Anaya-Lara O., Miller T.J.E. Power Electronic Control in Electrical Systems. Bodmin, MPG Books Ltd, Cornwall, 2002. 443 p. ISBN 0750651261.

2. Zhemerov G.G., Tugay D.V. Components of total electric energy losses power in PQR spatial coordinates. Electrical engineering \& electromechanics, 2016, no.2, pp. 11-20. (Rus). doi: 10.20998/2074-272X.2016.2.02.

3. Czarnecki L.S. What is wrong with the Budeanu concept of reactive and distortion power and why it should be abandoned. IEEE Transactions on Instrumentation and Measurement, 1987, vol.IM-36, no.3, pp. 834-837. doi: 10.1109/TIM.1987.6312797. 4. Nabae A., Tanaka T. A new definition of instantaneous active-reactive current and power based on instantaneous space vectors on polar coordinates in three-phase circuits. IEEE Transactions on Power Delivery, 1996, vol.11, no.3, pp. 12381243. doi: 10.1109/61.517477.

5. Akagi H., Watanabe E. H. and Aredes M. Instantaneous Power Theory and Applications to Power Conditioning. WileyIEEE Press, April 2007. 379 p. ISBN: 978-0-470-10761-4.

6. Akagi H., Kanazawa Y., Nabae A. Generalized theory of the instantaneous power in three phase circuits. Int. Power Electronics Conf., Tokyo, Japan, 1983, pp. 1375-1386.

7. Akagi H., Kanazawa Y., Nabae A. Instantaneous reactive power compensators comprising switching devices without energy storage components. IEEE Transactions on Industry Applications, 1984, vol.IA-20, no.3, pp. 625-630. doi: 10.1109/TIA.1984.4504460.

8. Peng F.Z., Ott G.W., Adams D.J. Harmonic and reactive power compensation based on the generalized instantaneous reactive power theory for three-phase four-wire systems. IEEE Transactions on Power Electronics, 1998, vol.13, no.6, pp. 1174-1181. doi: 10.1109/63.728344.

9. Yagup E.V. Optimization of the mode of asymmetric threephase system using an active filter and a modified control algorithm. Bulletin of the National Technical University «KhPI» Series: New solutions in modern technologies, 2016, no.42(1214), pp. 124-128. (Rus). doi: 10.20998/24134295.2016.42.20.

Received 27.08.2017

\section{E.V. Yagup, Candidate of Technical Science, Associate} Professor,

O.M. Beketov National University of Urban Economy in Kharkiv,

17, Marshal Bazhanov Str., Kharkiv, 61002, Ukraine, phone +380 577073114 ,

e-mail:kata3140@gmail.com

\section{How to cite this article:}

Yagup E.V. An active power filter at operation on the unbalanced and nonlinear loads with control by optimization algorithm. Electrical engineering \& electromechanics, 2017, no.5, pp. 23-26. doi: 10.20998/2074-272X.2017.5.03. 